\title{
Disheartened consumers: impact of malevolent apparel business practices on consumer's heart rates, perceived trust, and purchase intention
}

\author{
Jung Ha-Brookshire ${ }^{1 *}$ and Gargi Bhaduri ${ }^{2}$
}

\author{
*Correspondence: habrookshirej@ \\ missouri.edu \\ ${ }^{1}$ Department of Textile and Apparel \\ Management, University of Missouri \\ (137 Stanley Hall), Columbia, MO \\ 65201, USA \\ Full list of author information is \\ available at the end of the article
}

\begin{abstract}
In response to consumers' increasing desires to know about apparel businesses' ethical/responsible practices and the importance of trust between a firm and its consumers in today's marketplace, this study investigated how distrustful messages, specifically malevolent messages, affect consumers' perceived trust and purchase intention. The results of 67 participants' heart rate deceleration patterns and psychometric responses from a randomized experimental design showed that participants experienced greater heart rate deceleration during exposure to messages about a firm's malevolent business practices, than during messages about benevolence. Indeed, consumers seemed to get more disheartened when they were exposed to messages about malevolent business activities, and these messages seemed to affect consumers' perceived trust and purchase intention. The study concludes with important business implications for building and strengthening trust, or reducing and eliminating distrust, with consumers.
\end{abstract}

Keywords: Trust; Distrust; Intention; Consumer; Psychophysiology

\section{Introduction}

In today's highly competitive business environment, firms are not only concentrating on marketing their products and/or services but also on building strong relationships with customers to create their niche in the market. As much as fostering trust is important, reducing and alleviating distrust is also important when the firms are faced with negative images portrayed by the media. The global apparel industry has particularly suffered from consumers' distrust due to unethical business practices and untrustworthy supply chain issues in the past decades. For example, Nike, a U.S.-based activewear company, has been accused of child labor practices on various occasions (Boje \& Khan 2009). A recent fire killing over 100 workers in a garment factory in Bangladesh in 2012 is another example of apparel businesses' untrustworthy practices.

In the buyer-seller relationship, trust is defined as the buyer's (or the trustor's) willingness to be vulnerable to a seller (or the trustee) based on the belief that the seller will conduct business transactions as expected by the buyer (Pavlou \& Grefen 2004). The trust literature suggests that there are two dimensions of trust. One is credibility, which is defined as "the buyer's belief that a seller is competent, honest, and reliable, and will fulfill contractual requirements" (Dimoka 2010, p. 375). The other is 
benevolence, which is defined as "the buyer's belief that a seller has altruistic motives, is genuinely concerned with the buyer, and will act in a goodwill manner" (Dimoka 2010, p. 375).

On the opposite note, distrust is defined as "the buyer's unwillingness to be vulnerable to a seller on the basis that the seller will be inept, exhibit reckless behavior, violate obligations, not care about the buyer's welfare, act against the buyer's interests, even intend to harm the buyer" (Dimoka 2010, p. 376). Distrust, too, is found to have two distinct dimensions-discredibility and malevolence (Dimoka 2010). Discredibility refers to "the trustor's assessment of the potential of loss due to the trustees' incompetence, dishonesty, and unreliability," while malevolence refers to "the trustor's fear that the trustee will not act in his or her best interests" (Dimoka 2010, p. 378). Particularly, distrust due to malevolence indicates a concern that the trustee will engage in a harmful behavior with ill intention (Pavlou \& Dimoka 2006).

What is interesting here is that consumers may be affected by firms' benevolent or malevolent activities than credible or discredible activities. Credibility is related to contractual obligations; therefore, it is expected to be established between any legitimate firms and consumers. Many firms claim they are credible, so it is difficult for consumers to recognize which one is more credible than others. However, firms' benevolent or malevolent activities are thought to arouse humans' emotional responses; benevolence in particular is known to be the most influential form of trust (Lewicki \& Bunker 1995). Yet, the different impact that benevolence and malevolence may have on consumers' perceived trust and purchase intention is little explored. Therefore, this study examined the impact of benevolent and malevolent apparel business practices on consumers' heart rates and perceived trust. The difference in strengths of such impact between benevolent and malevolent practices was also evaluated. In the psychophysiology literature $e^{\mathrm{a}}$, when humans are exposed to emotionally arousing stimuli, such as malevolence in this study, they are believed to respond with a certain set of physiological reactions, including heart rate deceleration. Therefore, by examining both physiological and psychometric data, the findings were expected to help provide deep insights into the role of benevolence and malevolence in consumers' purchase intentions.

\section{Literature review}

\section{Benevolence vs. Malevolence}

Benevolence or malevolence is one of the key dimensions of trust or distrust. Benevolence is concerned with commitment and intentions of the trustee's good will; therefore, the trustor's emotional assessment of the trustee's positive behavior takes place (Dimoka 2010). Benevolence is different from credibility, which is believed to be associated with cognitive assessment of contracts, laws, and structural assurances (Williamson 1985). On the opposite note, malevolence is associated with the trustor's emotional assessment of the trustee's negative and/or harmful behavior. Malevolence is different from discredibility, which deals with the trustor's cognitive assessment of the potential loss through the trustee's incompetence and unreliability.

Although both benevolence (or malevolence) and credibility (or discredibility) are significant factors of trust (or distrust), the impact of benevolence is found to be much 
greater on trust than that of credibility (Pavlou \& Dimoka 2006). On the same note, malevolence affects distrust to a great degree than discredibility does (Lewicki \& Bunker 1995; Pavlou \& Dimoka 2006). In this light, for firms to enhance positive trusting relationships with consumers, reducing or eliminating distrust is as important as enhancing trust. Trust enhancement is expected to increase positive expectations about the firm's beneficial conduct, and reduction of distrust is to reduce negative expectations about the firm's harmful conduct (Kahneman \& Tversky 1979). More specifically, Pavlou and Dimoka (2006) found that when consumers were faced with messages regarding a company's benevolent activities, they believed that the company was less likely to engage in opportunistic behavior and therefore formed trust toward that company. In contrast, the evidence of opportunistic or malevolent behavior may lead consumers to believe that the company is highly likely to damage its reputation. This could result in reducing trust toward that company. The study therefore hypothesized:

H1: Benevolent messages about firm practices generate more positive perceived trust than malevolent messages do.

\section{Physiological responses to malevolence/benevolence}

The relationships between malevolent/benevolent messages and perceived trust/distrust can also be explored through the perspective of psychophysiology. Lang's (2000) limited capacity model of motivated mediated message processing (LC4MP) theory explains the relationships between human physiology and psychology. The foundational premises of the LC4MP is that humans have a limited amount of cognitive resources, which they strategically allocate to complete the mental tasks involved in perceiving, comprehending, and remembering information they encounter. Thus, when humans are exposed to new stimuli or messages, the cognitive system automatically selects information to be encoded into working memory and then stored in long-term memory.

LC4MP argues that one of the automatic cognitive selection mechanisms for information encoding, storage, and retrieval is the orienting response, or OR (Lang 2000). OR refers to humans' automatic physiological and behavioral reactions that occur in response to novel stimuli, or the "what-is-it?" response (Stern et al. 2001, p. 57). When an OR occurs, the viewer orients his or her sensory receptors toward the stimulus that caused the response. This orienting response results in an organized set of physiological responses as well as behavioral responses (Lynn 1966). One type of physiological response to a novel stimulus, an essential component of the orienting response, is heart rate deceleration (Bolls et al. 2001; Leshner et al. 2009).

LC4MP also suggests that emotional content in messages also automatically activate two fundamental motivational subsystems, the appetitive and the aversive (Berntson \& Cacioppo 2000). A major goal of the appetitive system is information intake, whereas that of the aversive system is protection. The appetitive system is more active than the aversive system when stimuli cause low to moderate arousal, a physiological and psychological state of being awake or activated to stimuli (Stern et al. 2001). In this light, when humans are exposed to negatively arousing stimuli, the aversive system becomes activated, leading the body and mind to allocate more cognitive resources to encode information about the negative stimuli. When the stimulus is aversive, the individual may shift cognitive resources among encoding, storage, and retrieval in order to engage in 
an appropriate defensive response to protect him or herself (Lang 2006). Thus, highly emotional and/or negative messages lead to a higher level of cognitive resources allocated to information processing (Leshner et al. 2009), and, consequently, higher heartrate deceleration.

In the context of trust and distrust in firm-consumer relationship, distrustful information on firms are known to be more important for consumers' perceived trust and buying behavior as they tend to place more weight on negative information than the positive of a similar magnitude (Ito et al. 1998). From the physiological perspective, Galletta and his colleagues (1995) found that distrustful information has a stronger effect on consumers' brain activities than trustful information due to the strong "emotional component" of its neural correlates. From the credibility and benevolence perspective, Dimoka (2010) found that the human brain's limbic system, typically associated with humans' emotions, was active when consumers were exposed to a company's benevolent and/or malevolent business activities. Therefore, malevolence-related messages are thought to active the social brain, the anterior paracingulate cortex, causing an orienting response with a greater degree of cognitive resources allocated to encoding them than benevolent messages (Dimoka 2010). Consequently, the study hypothesized:

H2: Participants will experience greater heart rate deceleration during exposure to messages about a firm's malevolent business practices than during exposure to messages about its benevolent business practices would.

\section{Trust and purchase intention}

Finally, the trust literature shows that consumers' perceived trust in a firm would increase consumers' future purchase intention. Bhattacherjee (2002) conceptualized trust as the consumer's belief in the firm's practices, and then showed that trust directly influences purchase intention. Li and Miniard (2006) concluded that consumers tend to have a higher purchase intention when they can trust a firm than when they cannot, and Büttner and Göritz (2008) also showed that firms' trustworthiness promotes consumers' purchase intention even in an online retail setting. That is, the more trustworthy a firm is, the more likely consumers would intend to purchase its products. However, what is unknown is whether perceived trust formed through benevolence or malevolence may have different impact on consumers' purchase intention. Therefore, the study hypothesized,

H3: The perceived trust formed through a firm's benevolent messages would have different impact on consumers' purchase intention than that formed through malevolent massages.

\section{Method}

\section{Within-subjects experimental design}

For the purpose of the study, a within-subjects experimental design was employed. The two sets of consumers' feedback comments on apparel business practices were developed following Pavlou and Dimoka (2006) and Dimoka (2010). Historically, apparel businesses have been in public scrutiny due to poor labor practices and untrustworthy retail practices (Bhaduri \& Ha-Brookshire 2011). Therefore, apparel businesses as the study stimuli deemed appropriate. The malevolent profile had four malevolent 
comments, such as "the apparel was a defective piece and the company did not bother to notify me about it" and "They charged me for the expensive apparel but never sent it to me!" and the benevolent profile had five benevolent comments, such as "Company went above what was necessary to complete this purchase despite many problems" and "Company went the extra distance to find the right product for me." Both profiles had eight credible comments, such as "Outstanding delivery and customer service" and "Ultra-fast purchase and fulfillment. Outstanding company!" to ensure the same level of credibility of each profile. This ensured the same level of credibility for both stimuli. The remaining 13 comments were ordinary comments that did not contain either positive or negative values, such as "Good purchase" or "Great service." All of these comments were developed and validated for their credibility, malevolence, benevolence, and ordinary natures by Pavlou and Dimoka (2006). Slight modifications of wordings were made to make stimuli appropriate for consumers' apparel shopping behavior.

\section{Dependent variables}

\section{Heart rates}

The electrical activity of the heart as recorded at the surface of the skin was measured by a technique known as electrocardiography, ECG, or EKG (Stern et al. 2001). Physiological signals were measured, amplified, and recorded using a MP36R Data Acquisition and Analysis System manufactured by Biopac Systems, Inc. linked to a computer with Acknowledge 4.1, a data acquisition and analysis software. Participants' heart rates were recorded by placing three $8 \mathrm{~mm} \mathrm{Ag/AgCl}$ (silver/silver-chloride) electrodes on each participant's upper right chest (positive), lower left waist (negative), and right ankle (ground). The signal was amplified and filtered by Acknowledge 4.1 equipped with high and low pass filtering. Both heart rate (the number of beats per minute) and interbeat interval (milliseconds between consecutive R-spikes in the complex QRS cardiac cycle) were collected. Prototypical ECG and electro-physiological events include a series of waves, including $\mathrm{P}, \mathrm{Q}, \mathrm{R}, \mathrm{S}, \mathrm{T}$, and $\mathrm{U}$. The QRS complex is the most prominent wave in the ECG, and interbeat interval is determined by measuring the time between $\mathrm{R}$ waves. $\mathrm{R}$ represents the peak of the QRS complex of the ECG wave (Stern et al. 2001).

\section{Perceived trust}

Perceived trust was measured through psychometric questions after participants were exposed to the study stimuli. The measurement items were adapted from Gefen (2002) and Pavlou (2002) and Dimoka (2010). The original scales (7-point Likert) were designed for a seller in an online auction site, and therefore, necessary changes were made to suit the purpose of the study. The measurement items for distrust (7-point Likert) were adapted from McKnight, Choudhury, and Kacmar (2002). The combined scores of trust and distrust yielded overall scores of perceived trust. The Cronbach alphas of the scales were .883 for the benevolence profile and .944 for the malevolence profile.

\section{Purchase intention}

Purchase intention was measured using Bhattacherjee's (2002) 3-item scale based on a 7-point Likert scale. The original items were modified to suit the purpose of the study. For example, the word "amazon" in the original questions was replaced by "this apparel firm" to meet the needs of the study. The Cronbach alpha of the 3-item purchase intention scale was 0.924 . 


\section{Data collection procedure}

After approval from the Institutional Review Board, participants were recruited for the study through advertisements in local news media in a U.S. mid-western city in 2011. The recruitment statements clearly showed that we were looking for "apparel shoppers" to ensure the participants were prepared to engage in apparel shopping situations during the data collection. A large retailer's gift card for the amount of $\$ 15$ was given as an incentive. In total, 76 participants were recruited. The data from nine participants were unusable; therefore, 67 participants were used for further analysis. This design met the sample size requirements suggested by Hair and his colleagues (2006). First, the minimum sample size per cell was greater than the number of dependent variables. Second, the sample size of 67 exceeded the minimum sample size per cell, 20, for repeated measure design (Hair et al. 2006).

Upon arrival, participants were briefed about the purpose, method, risks, and benefits of the study. After signing a written consent form, participants answered a set of demographic questions, including gender, ethnicity, age, marital status, education level, and income. An experimenter prepared each participant's skin by lightly buffing the surface of skin and attached electrodes to the participant. The experiment began once the participant expressed understanding of the procedure.

Stimulus presentation began through MediaLab v2010 with the study title and instructions, followed by a 10 -second baseline period in which participants saw a university's main website. After the baseline period, the MediaLab software presented a new screen with the instructions, including "Imagine that you are about to shop a pair of jeans. During the search of a new pair of jeans, you found other consumers' comments on a specific seller of jeans as next." After this screen, the first stimulus was presented in a random order. Participants were allowed to take as long as they wanted to read all the comments, and they were instructed to click a "continue" button when they were ready to move forward. A set of items measuring the participant's perceived trust was presented. Participants used a keyboard and a mouse to select and click the answer. Once this task was done, participants clicked a "continue" button, and the next stimulus was presented. The MediaLab v2010 program controlled stimulus presentation and randomized stimulus presentation order. Upon completion, we removed electrodes from participants, cleaned the skin, debriefed them, thanked them, handed over gift cards, and dismissed them. The entire experiment lasted approximately 30 minutes.

\section{Data analysis}

The heart rate data were reduced following Wise, Bolls, and Schaefer (2008). Because of individual differences in reading speed, the time spent reading each set of consumer feedback comments varied across participants. Thus, the whole time when participants were exposed to each stimulus (from immediately after the baseline period to the right before the participant clicked a 'continue' button prior to answering psychometric questions) was divided into three equal periods: beginning, middle, and end. Then, the average heart rates were computed for each period. This technique resulted in an equal number of segments that allowed repeated measures analyses of tonic (or resting) heart rate with three data points for each participant. This technique is known to be effective for tonic response analysis (Wise et al. 2008). 
Once data reduction was complete, the differences between the average heart rates of each segment and the baseline heart rates were calculated. This procedure helps eliminate individual differences in heart rates, as the difference between the heart rates of each segment and the baseline heart rates becomes a unit of analysis (Wise et al. 2008). The changes in heart rates were analyzed with repeated-measures analysis of variance (ANOVA). Mean comparisons were made for perceived trust and purchase intention. Simple regression analyses were conducted for the effect of perceived trust on purchase intention.

\section{Results}

\section{Sample characteristics}

Overall, 47 out of the 67 participants were women, and the rest were men. This was expected, as the recruitment statements included the phrase "apparel shopping behavior", and women seemed more interested in this study than men. Fifty-one participants indicated themselves as Caucasian, six as Asian or Pacific Islander, five as African American, and five as Other. Participants ranged from 18 years old to 69 years old, with an average age of 34.36. Approximately half of the participants were single or divorced, and the rest were either in a relationship or married. Half of the participants had some college or high school education, and, finally, over half of the participants had over U.S. $\$ 30,000$ as household income. Table 1 shows the characteristics of study samples.

\section{Manipulation checks}

Once the data were collected, manipulation of two trust profiles was checked by comparing perceived benevolence, using Pavlou and Dimoka's (2006) five-item, 7-point Likert-type scale of benevolence (Cronbach alpha $=.90$ ). Examples of items measuring benevolence were "This company is likely to care about my interests over theirs during the purchase" and "This company will do everything it can to give me the best purchase experience I could have".Overall, the perceived benevolence mean of the malevolent firm profile was 3.845 (S.D. $=1.167)$ and that of the benevolent firm profile was 5.917 (S.D. $=.896)$. The mean difference between the two were statistically significant $(t=10.974 ; p=.000)$, showing our two stimuli had significantly different levels of benevolence or malevolence.

\section{Hypotheseses tests}

Hypotheses 1 predicted Benevolent messages about firm practices generate more positive perceived trust than malevolent messages do. The perceived trust mean of the malevolent profile was 3.964 (S.D. $=1.177)$, and that of the benevolent profile was 5.805 (S.D. $=.705)$. Independent two-group $\mathrm{t}$-tests showed that that there is a statistically significant mean difference between these two means $(t=11.039 ; p=.000)$. These findings supported Hypothesis 1.

Hypothesis 2-that participants will experience greater heart rate deceleration during exposure to messages about a firm's malevolent business practices than during messages about its benevolence-was also supported. Multivariate test results showed the Time (3 factors, beginning, middle, and end) $\mathrm{X}$ Benevolence interaction was statistically significant $\left(F(2,131)=3.260, p=.042\right.$, partial $\left.-\eta^{2}=.047\right)$. The tests of within-subjects 
Table 1 Survey respondents' demographic characteristics

\begin{tabular}{|c|c|c|c|}
\hline \multirow{2}{*}{\multicolumn{2}{|c|}{$\frac{\text { Variable }}{\text { Gender }}$}} & \multirow[t]{2}{*}{ Frequency } & \multirow[t]{2}{*}{ Percentage } \\
\hline & & & \\
\hline & Male & 20 & $29.85 \%$ \\
\hline & Female & 47 & $70.15 \%$ \\
\hline \multicolumn{4}{|l|}{ Ethnicity } \\
\hline & Caucasian & 51 & $76.12 \%$ \\
\hline & African American/Black & 5 & $7.45 \%$ \\
\hline & Hispanic/Latino & 1 & $1.49 \%$ \\
\hline & Asian (including Indian) & 6 & $8.95 \%$ \\
\hline & Middle eastern & 1 & $1.49 \%$ \\
\hline & Pacific Islander & 1 & $1.49 \%$ \\
\hline & Others & 2 & $2.98 \%$ \\
\hline \multicolumn{4}{|l|}{ Age } \\
\hline & 21 and Under & 19 & $28.35 \%$ \\
\hline & 22 to 34 & 31 & $46.26 \%$ \\
\hline & 35 to 44 & 5 & $7.46 \%$ \\
\hline & 45 to 54 & 7 & $10.44 \%$ \\
\hline & 55 to 64 & 4 & $5.97 \%$ \\
\hline & 65 and Over & 1 & $1.49 \%$ \\
\hline \multicolumn{4}{|c|}{ Marital status } \\
\hline & In a relationship & 13 & $19.40 \%$ \\
\hline & Engaged & 1 & $1.49 \%$ \\
\hline & Single & 31 & $46.26 \%$ \\
\hline & Married & 17 & $25.39 \%$ \\
\hline & Divorced & 5 & $7.46 \%$ \\
\hline \multicolumn{4}{|c|}{ Education level } \\
\hline & Some high school education & 1 & $1.49 \%$ \\
\hline & High School degree & 4 & $5.97 \%$ \\
\hline & Some college education & 29 & $43.28 \%$ \\
\hline & College degree & 11 & $16.41 \%$ \\
\hline & Some graduate education & 7 & $10.44 \%$ \\
\hline & Graduate degree & 15 & $22.39 \%$ \\
\hline \multicolumn{4}{|l|}{ Income } \\
\hline & Less than $\$ 10,000$ & 13 & $19.5 \%$ \\
\hline & $\$ 10,000-\$ 29,999$ & 16 & $23.88 \%$ \\
\hline & $\$ 30,000-\$ 59,999$ & 14 & $19.44 \%$ \\
\hline & $\$ 60,000-\$ 9,999$ & 14 & $20.89 \%$ \\
\hline & $\$ 100,000-\$ 119,999$ & 7 & $10.44 \%$ \\
\hline & $\$ 120,000-\$ 199,999$ & 2 & $2.98 \%$ \\
\hline & $\$ 2000,000$ above & 1 & $1.49 \%$ \\
\hline
\end{tabular}

NOTE: Total number of participants $=67$.

contrasts showed that the Time $\mathrm{X}$ Benevolence interaction was specifically significant for the linear trend $\left(F(1,132)=6.436, p=.012\right.$, partial $\left.-\eta^{2}=.046\right)$. Figure 1 shows the heart rate changes over time and multivariate test results. 


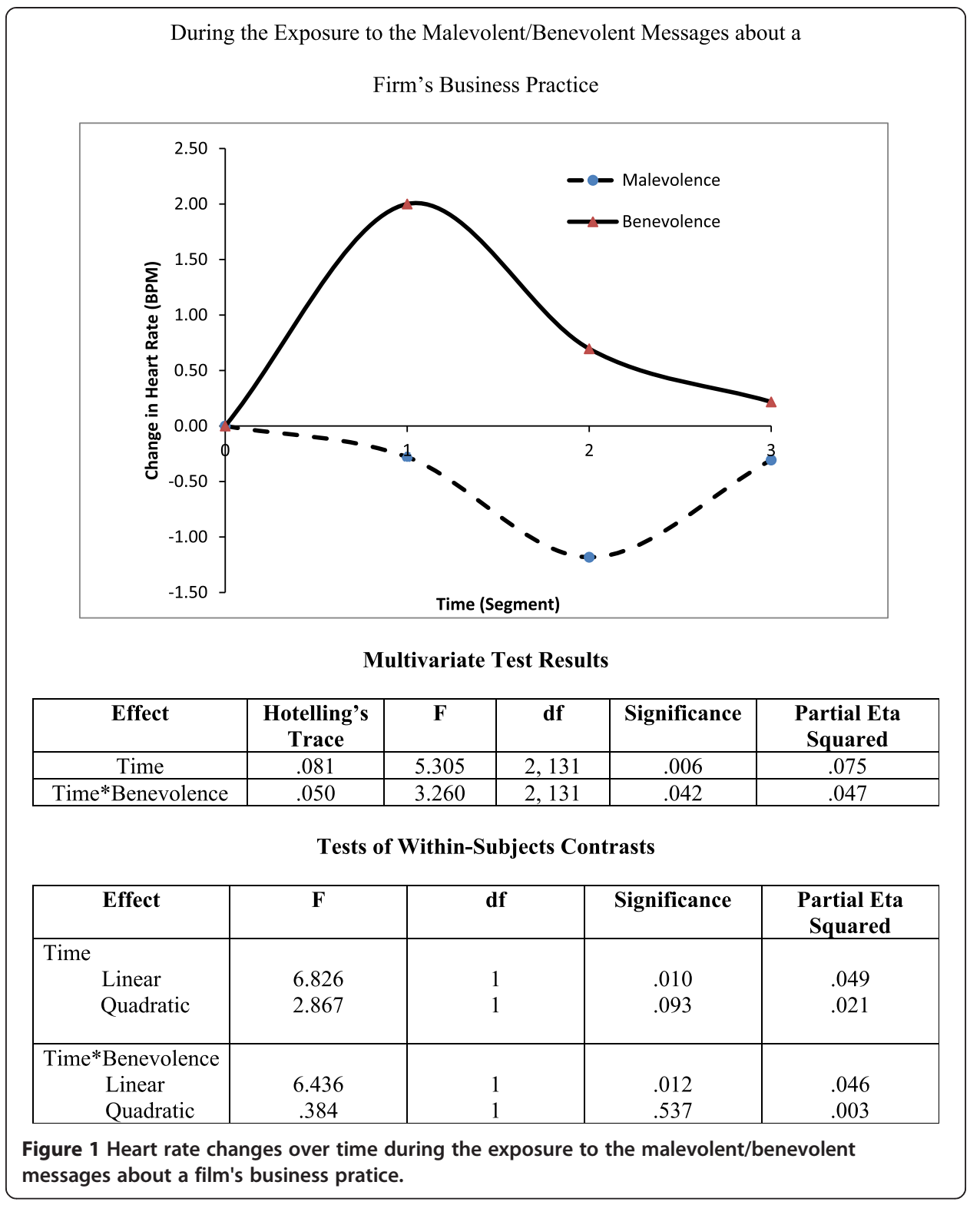

Hypothesis 3 suggested that the perceived trust formed through a firm's benevolence messages would have different impact on consumers' purchase intention from that formed through malevolence massages. The results of regression analysis showed that perceived trust had a statistically significant impact on purchase intention in both cases. However, the effect size of the perceived trust in case of benevolent or malevolent messages was significantly different. The impact of the perceived trust on purchase intention when participants was exposed to malevolent messages was much higher (standardized beta $=.794 ; p=.000$ ) than that of the benevolent messages (standardized beta $=.517 ; p=.000) .62 .7 \%$ of the variance was explained by the malevolent messages, while only $25.6 \%$ of the total variances were explained by the benevolent messages on overall purchase intention. Therefore, hypothesis 3 was also supported. Table 2 shows the results of regression analysis, demonstrating the effect of perceived trust on purchase intention. 
Table 2 Regression analysis results of the effect of perceived trust on purchase intention

\begin{tabular}{llll}
\hline Profile & Standardized beta & Sig & Adj R \\
\hline Malevolence & .794 & .000 & .627 \\
Benevolence & .517 & .000 & .256 \\
\hline
\end{tabular}

Note. Dependent variable: Purchase intention; Independent variable: Perceived trust.

\section{Conclusions}

As information technology advances, consumers now have more information than ever on what businesses do to whom and why. Some businesses take advantage of such exposure to share their trustworthy activities with consumers. Trust built from businesses' credible and benevolent practices can be an important factor for today's consumers' purchase decisions and their future behavior. On the other hand, a firm's bad reputation can also be easily shared with millions of people in a short period of time, quickly creating distrust between consumers and the firm. In many cases, it is extremely difficult to fully recover a reputation once distrust has been formed by consumers. Given the vulnerability to distrust from firms' malevolent conducts in the global apparel industry, the study investigated how the messages on a firm's malevolent practices of firms could affect consumers' physiological responses, perceived trust, and purchase intention, compared with the effect of benevolent practices.

The study findings showed that, first, participants experienced greater heart rate deceleration during exposure to messages about an apparel firm's malevolent business practices than benevolent practices. Indeed, consumers seemed to get disheartened by the firm's malevolent activities. Second, if an apparel firm is perceived to be malevolent, the study finding showed that consumers may see the firm as untrustworthy even if it may be a credible firm. In addition, when consumers were exposed to messages about the firm's malevolent business practices, perceived trust made a greater impact on the participant's overall purchase intention than when consumers were exposed to benevolent messages. This finding was consistent with heart rate deceleration patterns.

These findings have several important implications and contributions. First, the study results offer support for LC4MP by analyzing the participants' heart rate patterns. Particularly, the results supported the theory suggesting humans respond more strongly to aversive messages than appetitive messages. The heart rate deceleration patterns shown during consumers' responses to messages about a firm's malevolent practices clearly showed the negativity bias that Cacioppo and his colleagues (1999) explained.

Second, to our knowledge, this is one of the few attempts in the consumer literature to analyze humans' physiological responses as well as psychometric responses to investigate their trust and distrust. Psychophysiology has recently started gaining recognition for its importance in human science disciplines. Psychophysiology is expected to help advance the consumer behavior field, as the gap between consumers' attitudes and behaviors (that is, consumers do not always do what they said they would) has been found to be a problem in predicting consumer behavior (De Pelsmacker et al. 2005). An examination of the participants' physiological responses in addition to their verbal or psychometric responses would greatly help reduce this gap.

Third, the study findings showed the significant impact of malevolent apparel business practices on consumers' perceived trust or distrust and purchase intention. 
Malevolent business activities seem to catch consumers' attention significantly and affect their heart rate deceleration as well as produce low trust scores at a much greater rate than benevolent practices do. Therefore, if an apparel firm wants to build and maintain trust with consumers, it may want to put high priority on managing or alleviating malevolent practices.

As any other research, the study has limitations and, thus, future research opportunities. First, this experiment was conducted in a controlled laboratory environment. Certainly, this is not a normal, natural setting where average consumers read other consumers' feedback on certain firms or businesses. However, because the study used the differences of participants' heart rates between the experiment period and the baseline period, it was expected that any discrepancies caused by nervousness or anxiety could have been removed. Thus, interpretation of the study findings must be done with caution.

Second, the study used other consumers' comments available online as stimuli. Although many of today's consumers resort to online communities to see other people's opinions, they also rely on the opinions of family members, friends, or experts when forming trust or distrust. Thus, further research about the impact of information sources on consumers' trust and distrust is recommended.

Third, as much as heart rates showed interesting results in this study, direct connections between heart rate deceleration patterns and psychometric responses on perceived trust were not made in this current study. Therefore, further research is recommended to fulfill this gap. Also, in addition to heart rates, there are many other physiological responses that can be explored in consumer research. Skin conductance, electroencephalography (EEG), electromyography (EMG), and pupillography are other common metrics currently used in psychophysiology. Further research using such metrics would help advance consumer research tremendously.

\section{Endnote}

${ }^{a}$ Psychophysiology is a branch of psychology that is concerned with the physiological bases of psychological processes. The main subject matter of psychophysiology is the interaction of mind and body (Stern, Ray, \& Quigley 2001).

Competing interests

The authors declare that they have no competing interests.

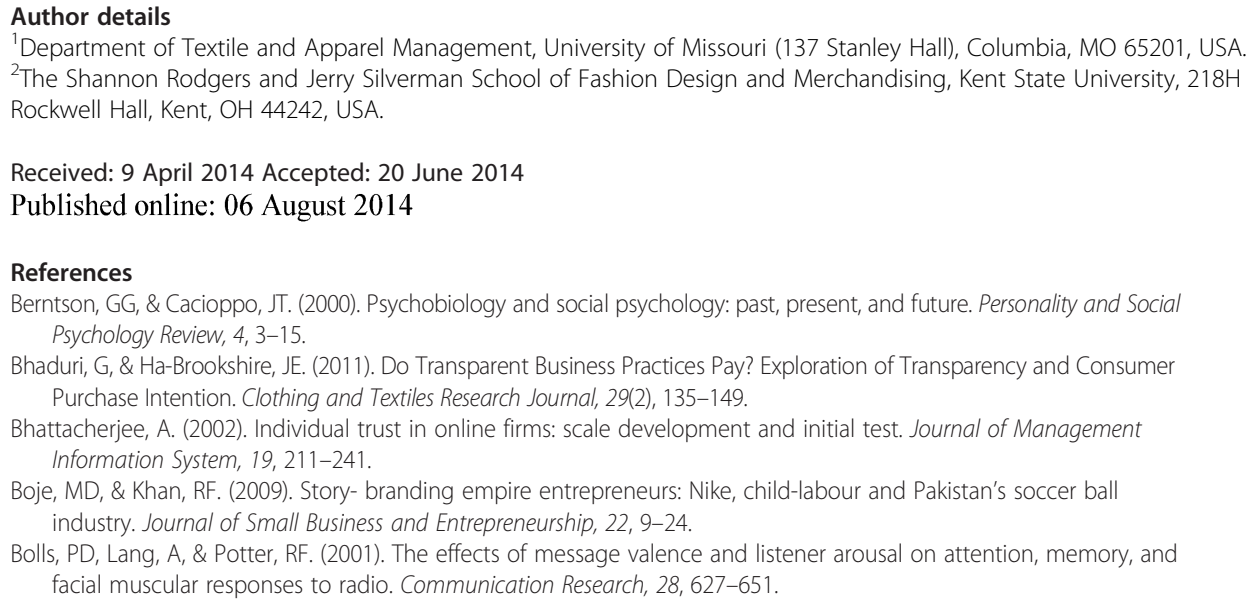

'Department of Textile and Apparel Management, University of Missouri (137 Stanley Hall), Columbia, MO 65201, USA ${ }^{2}$ The Shannon Rodgers and Jerry Silverman School of Fashion Design and Merchandising, Kent State University, 218H Rockwell Hall, Kent, OH 44242, USA.

Received: 9 April 2014 Accepted: 20 June 2014

Published online: 06 August 2014

\section{References}

Berntson, GG, \& Cacioppo, JT. (2000). Psychobiology and social psychology: past, present, and future. Personality and Social Psychology Review, 4, 3-15.

Bhaduri, G, \& Ha-Brookshire, JE. (2011). Do Transparent Business Practices Pay? Exploration of Transparency and Consumer Purchase Intention. Clothing and Textiles Research Journal, 29(2), 135-149.

Bhattacherjee, A. (2002). Individual trust in online firms: scale development and initial test. Journal of Management Information System, 19, 211-241.

Boje, MD, \& Khan, RF. (2009). Story- branding empire entrepreneurs: Nike, child-labour and Pakistan's soccer ball industry. Journal of Small Business and Entrepreneurship, 22, 9-24.

Bolls, PD, Lang, A, \& Potter, RF. (2001). The effects of message valence and listener arousal on attention, memory, and facial muscular responses to radio. Communication Research, 28, 627-651. 
Büttner, OB, \& Göritz, AS. (2008). Perceived trustworthiness of online shops. Journal of Consumer Behavior, 7, 35-50.

Cacioppo, JT, Gardner, WL, \& Berntson, GG. (1999). The affect system has parallel and integrative processing components: form follows function. Journal of Personality and Social Psychology, 76, 839-855.

De Pelsmacker, P, Driesen, L, \& Rayp, G. (2005). Do consumers care about ethics? Willingness to pay for fair-trade coffee. Journal of Consumer Affairs, 39, 363-385.

Dimoka, A. (2010). What does the brain tell us about trust and distrust? Evidence from a functional neuroimaging study. MIS Quarterly, 34, 373-396.

Galletta, DF, Ahuja, M, Hartman, A, Peace, AG, \& Teo, T. (1995). Social influence and end-user training. Communications of the $A C M, 38(7), 70-79$

Gefen, D. (2002). Reflections on the dimensions of trust and trustworthiness among online consumers. The DATA BASE for Advances of Information Systems, 33(3), 38-53.

Hair, JF, Black, WC, Babin, BJ, Anderson, RE, \& Tatham, RL. (2006). Multivariate data analysis. Upper Saddle River, NJ: Prentice-Hall.

Ito, TA, Larsen, JT, Smith, NK, \& Cacioppo, JT. (1998). Negative information weighs more heavily on the brain: the negativity bias in evaluative categorizations. Journal of Personality and Social Psychology, 75(4), 887.

Kahneman, D, \& Tversky, A. (1979). Prospect theory: an analysis of devision under risk. Econometrica, 47(2), 263-292.

Lang, A. (2000). The limited capacity model of mediated message processing. The Journal of Communication, 50, 46-70.

Lang, A. (2006). Using the limited capacity model of motivated mediated message processing to design effective cancer communication messages. The Journal of Communication, 56, S57-580.

Leshner, G, Bolls, P, \& Thomas, E. (2009). Scare' em or disgust 'em: the effects of graphic health promotion messages. Health Communication, 24, 447-458.

Lewicki, RJ, \& Bunker, BB. (1995). Trust in relationships: a model of development and decline. In BB Bunker \& JZ Rubin (Eds.), Conflict, cooperation, and justice. San Francisco, CA: Jossey-Bass.

Li, F, \& Miniard, PW. (2006). On the potential for advertising to facilitate trust in the advertising brand. Journal of Advertising, 35(4), 101-112.

Lynn, R. (1966). Attention, arousal, and the orientation reaction. Oxford, UK: Pergamon Press.

McKnight, DH, Choudhury, V, \& Kacmar, C. (2002). Developing and validating trust measures for e-commerce: an integrative typology. Information Systems Research, 13, 334-359.

Pavlou, PA. (2002). Institutional trust in interorganizational exchange relationships: the role of electronic B2B marketplaces. The Journal of Strategic Information Systems, 11, 215-243.

Pavlou, PA, \& Dimoka, A. (2006). The nature and role of feedback text comments in online marketplaces: implications for trust building, price premiums, and seller differentiation. Information Systems Research, 17, 391-412.

Pavlou, PA, \& Gefen, D. (2004). Building effective online marketplaces with institution-based trust. Information Systems Research, 15, 35-53.

Stern, RM, Ray, WJ, \& Quigley, KS. (2001). Psychophysiological recording (2nd ed.). New York, NY: Oxford University Press.

Williamson, OE. (1985). The economic institutions of capitalism. New York, NY: Free Press.

Wise, K, Bolls, PD, \& Schaefer, SR. (2008). Choosing and reading online news: How available choice affects cognitive processing. Journal of Broadcasting \& Electronic Media, 52, 69-85.

doi:10.1186/s40691-014-0010-9

Cite this article as: Ha-Brookshire and Bhaduri: Disheartened consumers: impact of malevolent apparel business practices on consumer's heart rates, perceived trust, and purchase intention. Fashion and Textiles 2014 1:10.

\section{Submit your manuscript to a SpringerOpen ${ }^{\circ}$ journal and benefit from:}

- Convenient online submission

Rigorous peer review

- Immediate publication on acceptance

- Open access: articles freely available online

- High visibility within the field

Retaining the copyright to your article

Submit your next manuscript at $\boldsymbol{\sim}$ springeropen.com 